\title{
BMJ Open Accuracy of popular media reporting on tobacco cessation therapy in substance abuse and mental health populations
}

\author{
David Krauth, Dorie Apollonio
}

To cite: Krauth $D$, Apollonio D. Accuracy of popular media reporting on tobacco cessation therapy in substance abuse and mental health populations. BMJ Open 2015;5:e007169. doi:10.1136/bmjopen-2014007169

- Prepublication history and additional material is available. To view please visit the journal (http://dx.doi.org/ 10.1136/bmjopen-2014007169).

Received 19 November 2014 Revised 17 February 2015 Accepted 9 March 2015
CrossMark

Department of Clinical Pharmacy, Philip R. Lee Institute for Health Policy Studies, University of California, San Francisco, San Francisco, California, USA

Correspondence to Dr Dorie Apollonio; dorie.apollonio@ucsf.edu

\section{ABSTRACT}

Background: Tobacco cessation therapy is not consistently provided for alcohol, drug abuse and mental health (ADM) populations, despite the enormous health consequences of tobacco addiction in these groups and research supporting the effectiveness of treatment. Policymakers, however, tend to rely on popular media reports rather than the scientific literature in regulating treatment. Our goal was to determine whether popular reporting accurately reflects findings from the scientific literature on tobacco cessation treatment for ADM populations in treatment.

Methods: We compared the results of systematic reviews on tobacco cessation therapy published before 2004 with articles published in traditional media and on the internet over the following 8 years. We searched LexisNexis and Google and assessed them using the Index of Scientific Quality (ISQ).

Results: We found that popular reporting on this topic was consistent with findings reported in contemporaneous scientific literature. Our results suggest that the failure to consistently provide tobacco cessation therapy to ADM populations in treatment is not due to poor research translation.

Conclusions: Our findings also suggest that in this topic area, scientific research findings have diffused relatively quickly. Further study of journalism in this area may suggest new strategies for effective translation of scientific findings into popular reporting on tobacco control.

\section{INTRODUCTION}

Patients receiving treatment for alcohol, drug abuse and mental health (ADM) problems are disproportionately affected by smoking. Tobacco use causes 435000 annual deaths in the USA, and approximately 200000 of these deaths occur in ADM populations, where smoking rates are 2-4 times greater than the general population. ${ }^{1-4}$ People with a mental illness or substance abuse disorder smoke nearly half of all the cigarettes smoked in the USA. ${ }^{5}$ Despite clinical evidence supporting the benefits of concurrent treatment and a desire and ability of

\section{Strengths and limitations of this study}

- This paper provides new evidence about translation of research from bedside to community in tobacco cessation therapy.

- Our exploratory study of Internet reporting reveals new insights about the relative role of evidence in Web versus traditional print media.

- Unlike a contemporaneous systematic review of scientific literature, we limited our inclusion criteria to articles published in English and drawn from a US news source.

- Although many of the news articles and websites we reviewed based their conclusions on whether or not smoking cessation interventions resulted in smoking reductions of any amount, systematic reviews of tobacco cessation focus on point prevalence abstinence.

- The majority of articles and websites we reviewed only categorised patients as alcoholics, drug abusers or those with mental illness, without discussing whether or not their conclusions depended on other patient characteristics such as age or sex.

patients to quit smoking, ${ }^{6-8}$ statewide policy diffusion has been slow and few states have mandated that mental health clinics and drug abuse centres require the provision of smoking cessation as a condition of licensure. ${ }^{9}$

There are many reasons for the poor translation of clinical evidence into policy, including the belief among healthcare providers that the health risks from smoking are less important than the perceived benefits of smoking, which are thought to calm psychiatric patients and reduce the risk of relapse. ${ }^{10}$ Other barriers include provider fears that trying to simultaneously quit smoking would compromise efforts to recover from other addictions, ${ }^{8}{ }^{11}$ questions regarding the best time to integrate smoking cessation treatment, and the fact that many individuals who staff drug abuse clinics and psychiatric wards are smokers themselves. ${ }^{10}$ 
A conceptual model of research translation details the process from the generation of clinical research to the uptake of research by journalists and other policy intermediaries who communicate directly with policymakers. However, a fundamental missing element in understanding research translation has been identifying the extent to which scientific research moves onto the policy agenda by attracting the attention of journalists. To address this knowledge gap, we have situated our discussion around two seminal studies favouring concurrent treatment: (1) a previous meta-analysis by Prochaska et $a l^{12}$ which found smoking cessation therapy was associated with a $25 \%$ increased likelihood of long-term abstinence from alcohol and illicit drugs and (2) a report by Covey et $a l^{13}$ concluding that administering smoking cessation therapy to patients with and without major depression produces equivalent smoking quit rates. By comparing these clinical research findings with journalistic claims about smoking cessation therapy in ADM populations, we can identify the extent to which clinical research findings have been translated into general knowledge.

The rationale for understanding how evidence moves along the research translation pathway is to enact evidence-based policy. The general public, health professionals, and policymakers rely heavily on journalistic reports to inform their healthcare decisions and policies. ${ }^{14}$ Research on policymaking also details the critical importance of journalists to communication within policymaking networks and in shaping constituency opinions. ${ }^{15}$ Although partisanship, ideology, and maintaining consistent voting records all factor into policymakers' decisions, policymakers also view the extent of public support for proposed policies as critical information in making decisions about whether to enact such changes. The extent and nature of press coverage of issues cues popular opinion and establishes the policy relevance of those issues, ${ }^{17-21}$ in particular increasing attention to existing problems and fostering demands for political action. Media messages are particularly relevant in establishing popular understanding of health risks and treatments. ${ }^{22-26}$ Journalists thus provide an independent source of information about the public relevance of proposed treatments to policymakers seeking to make decisions about systemic health interventions. ${ }^{27-30}$ However, media misunderstanding of research findings is common. ${ }^{23} 263132$

Journalists are known to play an important information-gathering role for policymakers but the degree to which journalists communicate with clinical researchers is unclear. Previous studies comparing popular news reports about scientific research to the journal articles that inspired them show a lack of consistency between author conclusions. ${ }^{23} \quad 26 \quad 27 \quad 32$ Furthermore, a review by HealthNewsReview.org covering 500 health news reports by US journalists determined that journalists often fail to discuss intervention costs, the validity of evidence presented, the magnitude of the findings (effects, risks, or costs), and alternative options. ${ }^{33}$ Consistent with these trends, we hypothesised (1) that popular reporting on smoking cessation relies on anecdotal evidence (as opposed to scientific) and will deviate from the scientific evidence and (2) that the majority of news reports we review are low-quality. If these hypotheses were correct, poor translation of research findings into the popular media could explain why policies on tobacco cessation are not informed by research evidence.

To test our hypotheses, we reviewed popular reporting of effects of smoking cessation therapy in ADM populations and relied on the Oxman et al ${ }^{14}$ instrument to assess report quality. We used both the Prochaska et al and Covey $e t$ al studies as a source of clinical evidence, which we compared with our review of popular reporting.

\section{METHODS}

Our analysis of research translation relies on reports from the popular media. We reviewed print articles and websites archived in the public domain that were most likely to be easily found by individuals inexperienced with traditional academic research methods. To identify traditional media (ie, print media) we searched the LexisNexis database for newspaper and magazine articles. To mirror electronic search strategies and identify internet media, we ran keyword searches through the most popular online search engine, Google.

\section{Inclusion criteria}

We included articles indexed in LexisNexis and websites in Google that we identified using defined keyword searches (table 1). We included: (1) major newspaper, magazine article, wire service stories, broadcast transcripts, internet content from independent bloggers, or websites containing either scientific or anecdotal claims regarding the effectiveness of smoking cessation in ADM populations, that were (2) published in English and (3) drawn from a US news source. Websites containing links to peer reviewed articles, news reports, grey literature, or fact sheets were included as long as these additional resources met the inclusion criteria.

\section{Exclusion criteria}

We excluded sources discussing smoking cessation therapy in ADM populations that assessed only nonsmoking related health outcomes. For example, assessments of whether or not alcoholics receiving smoking cessation therapy reduced their intake of alcohol were not included in the final review.

\section{Search strategy and article selection}

Our search strategy and terms are provided in table 1 . Studies were screened in two stages, as outlined in figure 1. Any articles or websites that did not clearly meet the 
Table 1 Search strategy and terms for traditional and internet media

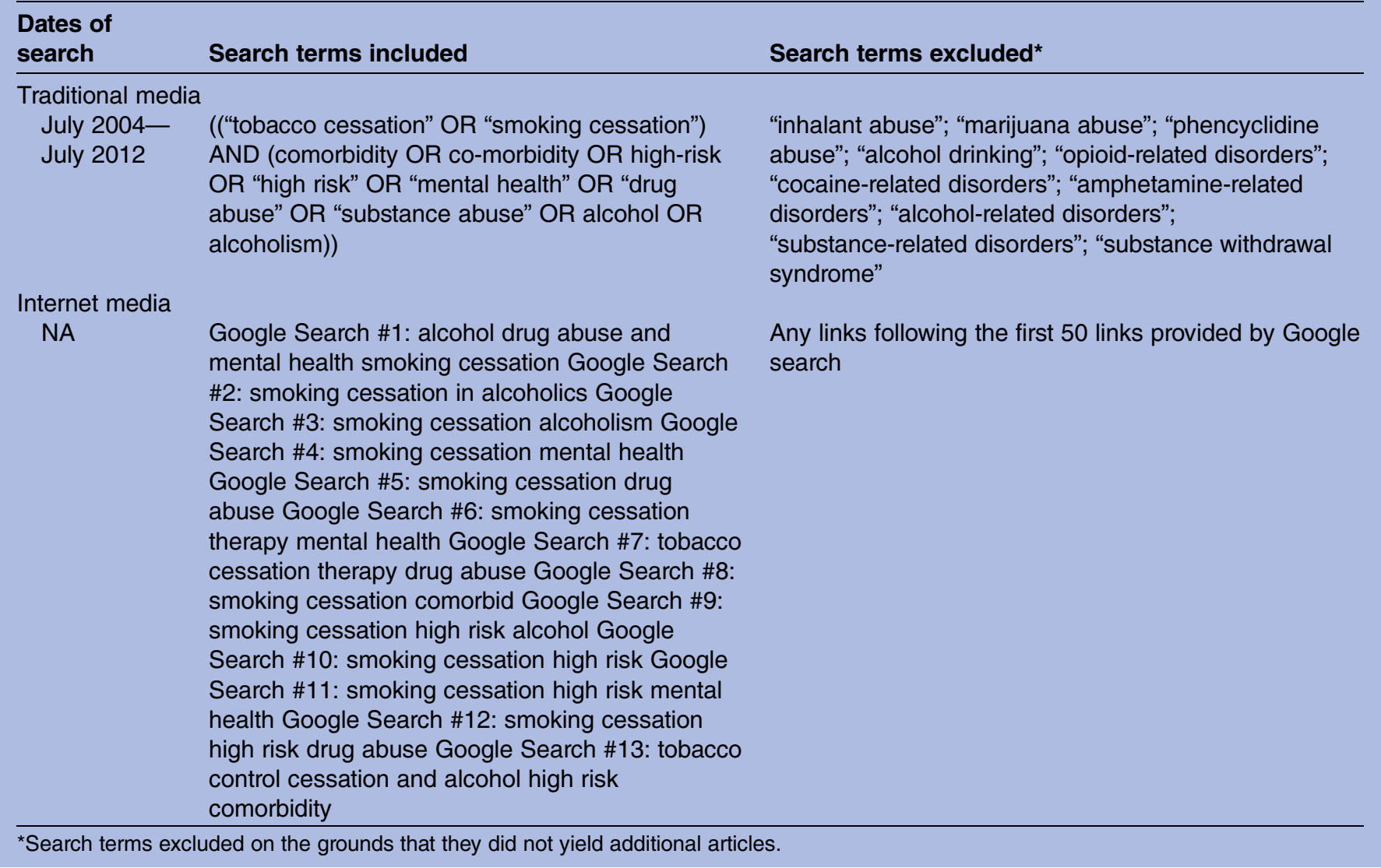

criteria were discussed by two authors (DA and DK) for a final decision about inclusion.

\section{Data extraction}

The following information was extracted from each article or website by one reviewer (DK):

A. Title of the article

B. Website URL address (if applicable)

C. Publication type (eg, newspaper, magazine article, wire service stories, broadcast transcripts, website)

D. Publication date (month/year)

E. Subpopulation (ie, alcohol, drug abuse, mental health) receiving the intervention

F. Source of evidence (scientific or personal anecdote)

In coding for content, two reviewers (DA and DK) assessed whether the article claimed that smoking cessation therapy was effective, ineffective, or made no judgment. Both coders worked independently and any discrepancies were discussed. A third coder was available to adjudicate any discrepancies and make a final decision if the discrepancy could not be resolved. The quality of each article was assessed using the Index of Scientific Quality (ISQ). ${ }^{14}$ We determined whether the following quality criteria were included:

1. Applicability: Describes whether or not the author clarifies to whom the information in the report applies

2. Opinions versus Facts: Describes whether or not facts are clearly distinguished from opinions
3. Validity: Describes whether or not the assessment of the credibility (validity) of the evidence is clear and well-founded (not misleading)

4. Magnitude: Describes whether or not the strength or magnitude of the findings (effects, risks, or costs) that are the main focus of the article are clearly reported

5. Precision: Describes whether or not the author provides a clear and well-founded (not misleading) assessment of the precision of any estimates that are reported or of the probability that any of the reported findings might be due to chance

6. Consistency: Describes whether or not the consistency of the evidence (between studies) is considered and whether the assessment is well-founded (not misleading)

7. Consequences: Describes whether or not all of the important consequences (benefits, risks, and costs) of concern relative to the central topic of the report are identified

8. Global: Describes the overall scientific quality of the report

9. Results-Describes the qualitative (eg, personal anecdotes) and quantitative (eg, relative risk values) data related to the efficacy of implementing smoking cessation interventions in ADM populations

10. Author conclusion-While item number 9 extracts data on the actual results of the article, this item 
Figure 1 Flow of included articles (traditional media only). $\mathrm{N}$ indicates the number of studies.a
Articles excluded for not meeting inclusion criteria: $\mathbf{N}=10,188$ pertains to the author conclusions regarding the efficacy of implementing smoking cessation interventions in $\mathrm{ADM}$ populations which may or may not agree with the empirical or qualitative data that is reported.

The ISQ index uses a five-point scale with a 5 corresponding to the highest level of quality. A score of 4 or 5 pertains to criteria containing clear references to evidence, while a score of 2 or 3 represents partly or definitely unclear references to evidence. An ISQ score of 1 or 2 is assigned to criteria where the evidence base is potentially misleading. We assigned reports with low overall quality (corresponding to low quality for several ISQ criteria) a score of 1 or 2 , and reports with high overall quality (corresponding to high quality for several ISQ criteria) a score of 4 or 5 .

\section{Analysis}

We report the frequency of each item assessed and analyse the content of popular news reports by generating summary statistics based on the content scores for all articles. Each item was assigned equal weight even though each item could differ in the extent it influenced the quality of the article. We compared the results for the subgroup of stories from traditional media to the subgroup of stories identified using Google, and assessed quality rankings for the overall sample and the subgroups (traditional and internet media) by reporting average quality scores.

\section{Comparison with scientific literature}

We compared our findings to (1) a previously published meta-analysis $^{12}$ which provided an empirical basis for
Potentially relevant articles identified and screened for retrieval:

$\mathrm{N}=10,216$
Articles excluded for not meeting inclusion criteria: $\mathbf{N}=\mathbf{2}$
Relevant articles meeting inclusion criteria:

$\mathbf{N}=\mathbf{2 6}$ supporting concurrent smoking cessation treatment in alcohol and drug abuse populations and (2) an earlier report which showed similar benefits for patients with depression. $^{13}$

\section{RESULTS}

As shown in figure 1, we identified 10216 potentially relevant articles in LexisNexis, of which 26 met our inclusion criteria and were included for analysis. Similarly, 650 websites were screened in Google, of which 26 met our inclusion criteria and were included for analysis.

\section{Traditional media}

Overall, 17 articles focused solely on tobacco cessation therapy in patients with mental health issues, one article focused solely on alcoholic patients, and one article focused solely on drug abuse patients. Four articles focused on tobacco cessation in patients having either alcohol, drug abuse, or mental health problems, two articles were limited to alcohol and drug abuse patients, and one article was limited to mental health and drug abuse patients. Of these articles, two were published in 2004, 1 in 2005, 5 in 2006, 4 in 2007, 3 in 2008, 2 in 2009, 4 in 2010, 3 in 2011, and 2 in 2012.

Among the 26 articles meeting our inclusion criteria in our LexisNexis search, 25 contained author conclusions that supported the use of concurrent tobacco cessation therapy in ADM populations and one article contained an ambiguous conclusion. Nineteen articles contained results that were based on quantitative data, four articles contained results based on minimal 
evidence, two articles did not contain any evidence and one article was supported by anecdotal claims.

\section{Article quality}

In table 2, we provide the mean values and SDs for each ISQ quality criteria for traditional and internet media. Each article clearly stated the generalisability of its results-'applicability' received an average score of 5. The item 'opinions versus facts' averaged 4.2 with 16 of 26 articles scoring a 5 for this category. An average score of 3.5 was assigned to the item consequences. Similarly, authors described the 'magnitude' of treatment effect infrequently-an average score of 3.4 was assigned to this item with 13 of 26 articles scoring a 5 for this item and 7 articles scoring a 1 . The item "validity" received an average score of 2.4 with only 1 article scoring a 5 for this item and 8 articles scoring a 1 . The item 'consistency' received an average score of 1.9 with individual scores ranging from 1 to 4 , while the item 'precision' received a score of 1.7 with individual results ranging from 1 to 3. Overall, the average 'global' score across all studies was 3.2. We provide a table of the data including the media sources and matrix of the review criteria in online supplementary table S1.

\section{Internet media}

Overall, 10 websites contained articles that focused solely on tobacco cessation therapy in patients with mental health issues, five articles focused solely on alcoholic patients, and no articles focused solely on drug abuse patients. Seven articles focused on tobacco cessation in patients having either alcohol, drug abuse or mental health problems, no articles were limited to alcohol and drug abuse patients, three articles were limited to mental health and drug abuse patients, and one article was limited to alcohol and mental health patients. Also, 13 of 26 websites assessed were published in the past 3 years, eight websites contained articles published between 2005 and 2009, and five websites contained articles without a publication date.

All 26 articles identified using Google contained author conclusions that supported the use of concurrent tobacco cessation therapy in ADM populations. Of these 26 articles, 23 articles contained results that were based on quantitative data, two articles contained results based on minimal evidence, and one article contained results based on quantitative and anecdotal evidence.

\section{Article quality}

Twenty-four of 26 articles clearly stated the generalisability of its results-'applicability' received an average score of 4.9. The item 'opinions versus facts' averaged 4.6 with 21 of 26 articles scoring a 5 for this category. An average score of 3.7 was assigned to the item 'consequences'. Similarly, most authors described the 'magnitude' of treatment effect only partially-an average score of 3.5 was assigned to this item with 11 of 26 articles scoring a 5 for this item, 13 articles scoring a 3 for this item, and two articles scoring a 1 . The item 'validity' received an average score of 2.7 with only one article scoring a 5 for this item and 7 articles scoring a 1 . The item 'consistency' received an average score of 2.9 with individual scores ranging from 1 to 5 , while the item 'precision' received a score of 2.3 with individual results ranging from 1 to 5 . Overall, the average 'global' score across all studies was 3.5. Mean and SD quality data is presented in table 2. We provide a table of the data including the media sources and matrix of the review criteria in online supplementary table S2.

\section{Comparison with scientific literature}

Overall, the 2004 meta-analysis by Prochaska et al ${ }^{12}$ found that intervention effects for smoking cessation were significant at post-treatment for alcoholic and drug abuse patients, but were no longer significant at 6-12 months follow-up. Specifically, patients receiving smoking cessation therapy experienced a twofold (relative risk of 2.03) increase in smoking abstinence following treatment. Our review found that popular reporting of tobacco cessation therapy in treatment matches the findings from Prochaska's study; authors reported a favourable conclusion regarding concurrent treatment of tobacco addiction in ADM patients in 25 of 25 articles or websites.

The report by Covey $e t a l^{13}$ found that quit rates for smokers receiving smoking cessation therapy were the same for patients with and without major depression and the depressive episodes were not adversely affected by the smoking intervention, a finding that supports concurrent treatment. Combining results for men and women, Covey reported that 13 of 49 (27\%) nonalcoholic patients with major depression successfully quit smoking while 30 of $110(27 \%)$ non-alcoholic patients without major depression successfully quit smoking. Likewise, we found that popular reporting expressed support for concurrent treatment of tobacco

Table 2 Summary statistics for article quality in traditional and internet media

\begin{tabular}{|c|c|c|c|c|c|c|c|c|}
\hline & Applicability & $\begin{array}{l}\text { Opinions } \\
\text { versus facts }\end{array}$ & Validity & Magnitude & Precision & Consistency & Consequences & Global \\
\hline Traditional media & $5.00 \pm 0.00$ & $4.15 \pm 1.19$ & $2.42 \pm 1.06$ & $3.42 \pm 1.75$ & $1.69 \pm 0.97$ & $1.92 \pm 1.06$ & $3.54 \pm 1.30$ & $3.16 \pm 0.61$ \\
\hline Internet media & $4.89 \pm 0.65$ & $4.58 \pm 0.90$ & $2.68 \pm 1.10$ & $3.53 \pm 1.26$ & $2.32 \pm 1.50$ & $2.89 \pm 1.39$ & $3.68 \pm 1.33$ & $3.51 \pm 0.79$ \\
\hline
\end{tabular}


addiction in psychiatric patients in 26 of 27 articles or websites.

\section{DISCUSSION}

Although we hypothesised that popular reporting of smoking cessation interventions for ADM populations would rely on anecdotal evidence, we found the opposite to be true. Most articles relied solely on quantitative estimates of tobacco reduction or abstinence. Moreover, consistent with the scientific literature, all but one article presented a favourable conclusion regarding smoking cessation therapy for ADM patients. Author conclusions were similar for LexisNexis and Google.

Our average quality scores for individual items and for pooled items (global) were also comparable for LexisNexis and Google. The item 'applicability' differed by only 0.1 (ie, 5.0 vs 4.9 for LexisNexis and Google, respectively). The item 'consistency' had the largest difference (ie, 1.9 vs 2.9 for LexisNexis and Google, respectively).

The publication dates for our LexisNexis articles or Google websites ranged from 2004 to 2012. 17 of 26 LexisNexis articles were published before 2010. However, only 8 of 26 Google websites were published before 2010. Although this would suggest that clinical findings are diffused into traditional print media (ie, LexisNexis) faster relative to Web media (ie, Google), it is possible we missed earlier publications archived by Google since we only reviewed the first five web pages from each search.

\section{Study limitations}

A limitation of our study is that we may not have identified all published articles in LexisNexis. As we limited our inclusion criteria to only articles published in English and drawn from a US news source, it is possible some articles were missed. Moreover, we cannot rule out the possibility that non-US news reports could have higher quality or different author conclusions regarding concurrent smoking cessation treatment in ADM populations. The systematic review of scientific literature written by Prochaska $e t a l^{12}$ did not limit their inclusion criteria to English only articles or studies based in the USA.

Our comparison with the scientific evidence is further limited by the fact that the contemporaneous systematic review $^{12}$ only included articles that reported point prevalence abstinence, excluding articles that only reported on smoking reduction. However, many of the news articles and websites we reviewed based their conclusions on whether or not smoking cessation interventions resulted in smoking reductions of any amount. Our comparison with the article by Covey et $a l^{13}$ is limited since that article only assessed smoking cessation therapy effects in patients who had major depression. However, most of our findings from LexisNexis or Google did not describe which mental health condition patients undergoing smoking cessation had, or described a different mental health condition such as schizophrenia.
Moreover, the patient backgrounds were adequately described by both Prochaska $e t a^{12}$ and Covey et al ${ }^{13}$ and patients not meeting the a priori defined inclusion criteria were excluded. The majority of articles and websites we reviewed only categorised patients as alcoholics, drug abusers or those with mental illness, without discussing whether or not their conclusions depended on other patient characteristics such as age or sex.

\section{CONCLUSION}

Our findings provide new evidence about translation of research from bedside to community in tobacco cessation therapy. We present two new innovations in discussing popular reporting on health: we compare popular reporting to a contemporaneous systematic review, and include online media as well as traditional reporting. We find that popular reporting on this topic is high-quality and mirrors the results of existing clinical data. Our results also suggest that scientific research on this topic diffused relatively quickly into popular reporting. Further study of journalists reporting in this area might identify useful research translation strategies for other areas of tobacco control. Finally, our exploratory study of Internet reporting provides new insights about the relative role of evidence in Web versus traditional print media. Our results suggest that the continuing limited provision of tobacco cessation therapy in drug abuse and mental health treatment is not due to poor research translation.

Acknowledgements The authors acknowledge Dr Lisa Bero for reviewing drafts of our manuscript.

Contributors DA and DK conceived and designed the study, collected and analysed the data, and wrote and approved the final draft of the paper. DK submitted the study. Both authors also had full access to all of the data in the study and take responsibility for the integrity of the data and the accuracy of the data analysis.

Funding This work was supported by the National Cancer Institute, grant \#1K07CA140236.

\section{Competing interests None.}

Provenance and peer review Not commissioned; externally peer reviewed.

Data sharing statement Extra data can be accessed via the Dryad data repository at http://datadryad.org/ with the doi:10.5061/dryad.j646b.

Open Access This is an Open Access article distributed in accordance with the Creative Commons Attribution Non Commercial (CC BY-NC 4.0) license, which permits others to distribute, remix, adapt, build upon this work noncommercially, and license their derivative works on different terms, provided the original work is properly cited and the use is non-commercial. See: http:// creativecommons.org/licenses/by-nc/4.0/

\section{REFERENCES}

1. Schroeder SA. A 51-year-old woman with bipolar disorder who wants to quit smoking. JAMA 2009;301:522-31.

2. National Youth Tobacco Survey. In: Centers for Disease Control and Prevention, editor. Atlanta, GA, 2009.

3. Mauer B. Morbidity and mortality in people with serious mental illness. In: Parks J, Svendsen D, Singer P, Foti M, eds. Alexandria, VA: National Association of State Mental Health Program Directors Medical Directors Council, 2006. 
4. Williams JM, Ziedonis D. Addressing tobacco among individuals with a mental illness or an addiction. Addict Behav 2004;29:1067-83.

5. Lasser K, Wesley BJ, Woolhandler S, et al. Smoking and mental illness: a population-based prevalence study. JAMA 2000;284: 2606-10.

6. Hughes JR, Novy P, Hatsukami D, et al. Efficacy of nicotine patch in smokers with a history of alcoholism. Alcohol Clin Exp Res 2003;27:946-54.

7. Richter K, McCool R, Okuyemi KS, et al. Patients' views on smoking cessation and tobacco harm reduction during treatment. Nicotine Tob Res 2002;4(Supple):175-82.

8. Richter K. Good and bad times for treating cigarette smoking in drug treatment. J Psychoactive Drugs 2006;38:311-15.

9. Krauth D, Apollonio D. State-level tobacco cessation programs for individuals in substance abuse treatment facilities. Seattle, Washington: Society for Research on Nicotine and Tobacco, 2014.

10. Apollonio D, Philipps R, Bero LA. Tobacco cessation intervention versus placebo for tobacco addiction in individuals in alcohol or substance abuse treatment or recovery. Cochrane Database Syst Rev 2012; forthcoming.

11. Goldsmith R, Knapp J. Towards a broader view of recovery. J Subst Abuse Treat 1993;10:107-11.

12. Prochaska JJ, Delucchi K, Hall SM. A meta-analysis of smoking cessation interventions with individuals in substance abuse treatment or recovery. J Consult Clin Psychol 2004;72:1144-56.

13. Covey LS, Glassman AH, Stetner F, et al. Effect of history of alcoholism or major depression on smoking cessation. $A m \mathrm{~J}$ Psychiatry 1993;150:1546-7.

14. Oxman $A D$, Guyatt $G H$, Cook DJ, et al. An index of scientific quality for health reports in the lay press. $J$ Clin Epidemiol 1993;46:987-1001.

15. Jamieson AM. The messenger as policy maker: thinking about the press and policy networks in the Washington community. Democracy and North America, 114-32.

16. Hallin DC. The media, the wair in Vietnam, and political support: a critique of the thesis of an oppositional media. $J$ Politics 1984;46:2-24.

17. Page BI, Shapiro RY, Dempsey GR. What Moves Public Opinion? Am Political Sci Rev 1987;81:23-43.
18. Cobb MD, Kuklinski JH. Changing minds: political arguments and political persuasion. Am J Political Sci 1997;41:88-121.

19. Hetherington MJ. The media's role in forming voters' national economic evaluations in 1992. Am J Political Sci 1996; 40:372-95.

20. lyengar S, Peters MD, Kinder DR. Experimental demonstrations of the "not-so-minimal" consequences of television news programs. Am Political Sci Rev 1982;76:848-58.

21. Krosnick JA, Kinder DR. Altering the foundations of support for the president through priming. Am Pol Sci Rev 1990;84:497-512.

22. McComas KA. Defining moments in risk communication research: 1996-2005. J Health Commun 2006;11:75-91.

23. Schwitzer G. How the media left the evidence out in the cold. Br Med J 2003;326:1403-4.

24. Grilli R, Ramsay C, Minozzi S. Mass media interventions: effects on health services utilization. Cochrane Database Syst Rev 2001(4): CD000389.

25. Phillips DP, Kanter EJ, Bednarczyk B, et al. Importance of the lay press in the transmission of medical knowledge to the scientific community. N Engl J Med 1991;325:1180-3.

26. Moynihan R, Bero LA, Ross-Degnan D, et al. Coverage by the News Media of the Benefits and Risks of Medications. N Engl J Med 2000;342:1645-50.

27. Winsten JA. Science and the media: the boundaries of truth. Health Aff 1985;4:5-23.

28. Steinbrook R. Medical journals and medical reporting. $N$ Engl J Med 2000;342:1668-71.

29. Smith R. Medical journals and the mass media: moving from love and hate to love. N Engl J Med 2006;99:347-52.

30. Taroni F, Grilli R. Mass media interventions. Int Encyclopedia Public Health 2008:202-10.

31. Fielding J, Marks J, Myers B, et al. How do we translate science into public health policy and law? J Law Med Ethics 2002;30(3 suppl): s22-32.

32. Remuzzi G, Schieppati A. Lessons from the Di Bella affair. Lancet 1999;353:1289-190.

33. Schwitzer G. How do US journalists cover treatments, tests, products, and procedures? An evaluation of 500 stories. PLoS Med 2008;5:e95. 